\title{
A eXPeriênCIa da Pesquisa e da ORIENTaÇão:
}

\author{
UMA ANÁLISE GENEALÓGICA
}

\author{
João Leite Ferreira Neto ${ }^{\star}$
}

\begin{abstract}
Resumo
O artigo discute vicissitudes do trabalho de pesquisa e de orientação em pósgraduação numa interlocução com um enfoque genealógico foucaultiano. Realiza uma análise conceitual sobre método em Foucault contraposto à perspectiva cartesiana. Apresenta elementos para um diagnóstico do presente da pesquisa nas áreas de ciências humanas no Brasil, a partir de estudos de outros pesquisadores e de levantamento feito com mestrandos em Psicologia. Realça a importância da discussão metodológica na pesquisa; analisa aspectos táticos e problematizantes dos projetos de pesquisa enviados para agências de fomento; discute parâmetros de avaliação da função e da relevância da pesquisa nessas áreas.
\end{abstract}

Palavras-chave: pesquisa; orientação; pós-graduação; Foucault; genealogia; metodologia.

\section{RESEARCH AND TUTORING EXPERIENCE:}

\section{A GENEALOGIC ANALYSIS}

\begin{abstract}
The paper discusses vicissitudes of research and tutoring in postgraduate programs through a dialogue with foucauldian genealogy. It makes a conceptual analysis about the foucauldian method in contraposition with Descarte's perspective. It presents some elements for a diagnosis of the present of the research in the field of human sciences in Brazil, working with studies of another researchers and a survey with psychology's scholars. It highlights the importance of a methodological discussion in research process; analyzes tactic and problematizing aspects of research projects submitted to funding agencies; discusses assesment parameters of the function and the relevance for researches in this field.
\end{abstract}

Keywords: research; tutoring; postgraduate programs; Foucault; genealogy; methodology.

\footnotetext{
^ Professor do programa de pró-graduação em psicologia da PUC Minas - , doutor em psicologia (PUC-SP). Endereço: Pontifícia Universidade Católica de Minas Gerais, Instituto de Psicologia. Av. Dom José Gaspar, 500. Prédio 12 Coração Eucarístico. CEP: 30535-610 - Belo Horizonte, MG - Brasil.

E-mail: jleite.bhe@terra.com.br
} 
O objetivo deste artigo é discutir algumas vicissitudes da experiência de pesquisa e de orientação em pós-graduação, numa interlocução com a obra de Foucault e seu enfoque genealógico. Foucault (1984, p. 10) entende a experiência como "a correlação, numa cultura, entre campos de saber, tipos de normatividade e formas de subjetividade". Portanto, a pesquisa como experiência envolve não somente a produção de saberes a partir de procedimentos considerados científicos, mas composição uma relação complexa entre saberes, poderes e modos de subjetivação que será analisada neste texto. Para tanto, realizaremos primeiramente uma discussão conceitual sobre método em Foucault em contraposição à perspectiva, mais clássica, de Descartes. Em segundo lugar, apresentaremos alguns elementos para um diagnóstico do presente no campo da pesquisa em ciências humanas e sociais no Brasil, a partir de análises realizadas por outros pesquisadores e levantamento feito com mestrandos de um programa de pósgraduação. No final apontaremos algumas direções para o trabalho de pesquisa e orientação na pós-graduação

\section{Diálogo metodológico de Foucault com Descartes}

Em outro trabalho desenvolvi uma reflexão sobre metodologia a partir das contribuições de Foucault (FERREIRA NETO, 2004), em cuja obra o sentido da metodologia é ético. Ela é entendida como um conjunto de "práticas de si" para produção de um sujeito ético (FOUCAULT, 1984). Para Foucault (2004, p. 240), o trabalho de pesquisa consiste num movimento de desprender-se de si mesmo (se dépendre de soi-même), numa "tentativa de modificar o que se pensa e mesmo o que se é". Portanto, é um processo não somente cognitivo, mas também ontológico. Sua perspectiva possui um claro contraste com a de Descartes (1983, p. 25) em seu Discurso do método, cujo subtítulo revelador é "para bem conduzir a própria razão e procurar a verdade nas ciências", que enfatiza a dimensão instrumental do método. Trata-se, pois aqui, inicialmente, de explorar as diferenças entre uma concepção de método que enfatiza sua dimensão ética e outra que enfatiza sua dimensão instrumental.

O método cartesiano é produzido pelo intenso "desejo de aprender a distinguir o verdadeiro do falso para [...] caminhar com segurança na vida" (DESCARTES, 1983, p. 33) buscando a certeza e a verdade na aquisição do conhecimento. Seu ponto de partida é o postulado de que todos os homens são dotados de bom senso, mas somente a boa aplicação da razão, consubstanciada no método, "o caminho reto", pode garantir o verdadeiro conhecimento (DESCARTES, 1983, p. 29). Este não pode ser encontrado na tradição, na opinião da maioria ou no discurso dos mestres, mas na aplicação meticulosa e diligente dos preceitos do método, que lhe assegura o alcance da verdade (DESCARTES, 1983, p. 36).

Descartes acredita, como bom moderno, no ordenamento matemático da natureza. A verdade é una e universal. Qualquer criança que faça uma adição segundo as regras pode estar certa de haver encontrado "tudo o que o espírito humano poderia achar [...] Pois, enfim, o método que ensina a seguir a verdadeira ordem e a enumerar exatamente todas as circunstâncias daquilo que se procura, 
contém tudo quanto dá certeza às regras da matemática" (DESCARTES, 1983, p. 40). Em resumo, o método é um conjunto de procedimentos racionais, de base lógico-matemática, que garante a qualquer sujeito que dele se utilizar a aquisição do conhecimento verdadeiro e a refutação do falso. São os procedimentos racionais que asseguram o acesso à verdade.

No Discurso do Método, Descartes enuncia quatro preceitos metodológicos. O primeiro deles é o da evidência: jamais aceitar uma coisa como verdadeira, que não se apresentasse evidentemente como tal. A evidência procede da clareza e distinção das idéias provenientes da razão, e estabelece que nada deve ser incluído nos juízos que não se apresente de modo claro e distinto, sem qualquer margem de dúvida. O segundo é o da análise: dividir cada dificuldade para examiná-la em tantas parcelas quanto possível e necessário, para melhor resolvê-las. O terceiro, o da síntese: ordenar os pensamentos começando pelos objetos mais simples até uma ordem mais complexa. O último, o da enumeração: fazer enumerações completas e revisões seguras de modo a não haver omissões.

A idéia da evidência, busca das coisas claras, distintas e indubitáveis é o motor do método cartesiano. Com ela corroboram a importância da matemática, a crença no ordenamento do mundo e a busca da exaustividade.

A marca do discurso cartesiano é a de que a busca da verdade da ciência é obra de um homem só, existindo um forte laço entre método e individualidade. A obra perfeita é aquela na qual um só homem trabalhou (DESCARTES, 1983, p. 34), e ele não deve contentar-se com as opiniões de outrem, mas empregar o próprio juízo em examiná-las (DESCARTES, 1983, p.44).

Descartes (1983, p. 30) insiste que seu “designo não é ensinar o método que cada qual deve seguir para conduzir sua razão", mas apenas expor o modo que ele utilizou para conduzir a sua. Seu testemunho é dirigido a todos "que unem o bom senso ao estudo" ao invés de confiar apenas nos livros antigos (DESCARTES, 1983, p. 71). Por isso, seu esforço de divulgação do método através de uma escrita em língua vulgar (francês) ao invés da língua erudita (latim) e uma exposição marcada pela clareza e simplicidade. Ele escreve em busca de diálogo com os homens de bom senso que suportam a ignorância e o demorado trabalho que exige a busca da verdade e não se satisfazem com a verossimilhança fruto de pura vaidade (p.68). Em suma, trata-se do trabalho de aplicação rigorosa da razão consubstanciada na simplicidade do método a única garantia de acesso, sem erro, à verdade.

Descartes (1983, p. 41) também assume uma dimensão ética em seu método, por ele chamado de "uma moral provisória", um ambiente onde o pesquisador possa se alojar comodamente durante o tempo do trabalho, de modo a evitar a impermanência própria da situação investigativa.

Contrário a isso, Foucault considera que a impermanência não deve ser evitada, mas se constitui como condição de possibilidade para o trabalho investigativo. Afinal, "de que valeria a obstinação do saber se ele assegurasse apenas a aquisição dos conhecimentos e não, de certa maneira, e tanto quanto possível, o 
descaminho daquele que conhece?" (FOUCAULT, 1984, p. 13). Como ele afirma em um artigo, trata-se de uma "moral do desconforto" (FOUCAULT, 1994, p. 787), oposta à "moral cômoda" cartesiana.

Foucault considera que Descartes estabeleceu uma ruptura com o pensamento filosófico anterior que associava ética, como prática de si, e conhecimento do mundo - tradição que vai dos gregos até os filósofos do século XVII, para a qual "não há acesso à verdade sem ascese" (FOUCAULT, 1994, p. 277). Assim, Descartes operou uma ruptura entre ética e verdade. Agora é suficiente ser qualquer sujeito a quem basta ver o que é evidente. A evidência substitui o trabalho ético sobre si - basta o método como garantia de acesso à verdade. Nas palavras de Foucault (1994, p. 277): “Com Descartes a evidência direta é suficiente. Depois de Descartes, temos um sujeito não ascético de saber. Esta mudança possibilita a institucionalização da ciência moderna".

Foucault localiza duas dificuldades nas formulações metodológicas cartesianas. A primeira é a concepção de sujeito do conhecimento. O sujeito do conhecimento em Descartes, sujeito do cogito, agente do percurso metodológico na direção do verdadeiro conhecimento, se apresenta como universal e anistórico. Foucault vai salientar que se trata de um sujeito que é todo mundo, em todo lugar e a todo o momento e, por essa razão, não pode ser tomado como operador dentro de sua proposta de uma ontologia crítica.

A segunda dificuldade é a concepção cartesiana de produção de conhecimento decorrente da idéia de método como caminho a priori, que garante o acesso à verdade a qualquer sujeito que dele se utilize. Foucault propõe que se substitua a neutralidade da metodologia correta por uma ética de auto-invenção, em que sujeito e objeto são constituídos no próprio processo de investigação. Portanto, em sua ontologia crítica, Foucault associa pesquisa e processos de subjetivação.

Em várias ocasiões, Foucault, discutiu o tema da metodologia em sua obra. Entretanto, seu livro considerado mais diretamente metodológico, A arqueologia do saber (FOUCAULT, 1972), é mais um desenvolvimento de seu pensamento que o esclarecimento de uma suposta unidade metodológica de seus livros anteriores. Em entrevista datada de 1997, quando inquirido sobre nunca haver fixado um método, ele confirma e acrescenta:

\begin{abstract}
Arqueologia do saber não é um livro de metodologia. Não tenho um método que se aplicaria, do mesmo modo, a domínios diferentes. Ao contrário, diria que é um mesmo campo de objetos que procuro isolar, utilizando instrumentos encontrados ou forjados por mim, no exato momento em que faço minha pesquisa, mas sem privilegiar de modo algum o problema do método [...] Eu tateio, fabrico como posso instrumentos que são destinados a fazer objetos (FOUCAULT, 2003a, p. 229).
\end{abstract}


Portanto, o ato de pesquisar produz objetos de pesquisa a partir de um método que não é pré-definido, e nesse mesmo movimento é constituído o sujeito pesquisador. Foucault (2003a, p. 230) considera o solo de sua pesquisa minado e perigoso, possuidor de um objeto cambiante: "o que somos - os conflitos, as tensões, as angústias que nos atravessam”. Ou seja, nesse solo comparecem conjuntamente sujeito e objeto.

Nessa mesma direção crítica, mas oriundo do contexto norte-americano, o sociólogo Howard Becker (1999, p. 18) acusa a metodologia de ser uma disciplina proselitizante, por uma tendência de certos metodólogos de apregoar "uma maneira certa de fazer as coisas", querendo converter os outros à sua causa, vendendo a metodologia como salvação.

Becker (1999, p. 19) denuncia o padrão comum dessas pesquisas: "preocupação com métodos quantitativos, com a concepção a priori da pesquisa, com técnicas que minimizem a chance de obter conclusões não confiáveis devido à variabilidade incontrolada de nossos procedimentos". Os procedimentos recomendados têm em comum a diminuição da área onde o julgamento humano pode operar, substituindo-o pela aplicação de uma regra de procedimento. Curiosamente, no entanto, na sociologia americana, os trabalhos mais premiados lançaram mão de outros recursos metodológicos (observação participante, pesquisa histórica e estratégias de triangulação de procedimentos) diferentes dos recomendados. A proposta de Becker (1999, p. 12) lembra a descrição de Foucault apresentada anteriormente:

Prefiro um modelo artesanal de ciência, no qual cada trabalhador produz as teorias e métodos necessários para o trabalho que está sendo feito [...] os sociólogos deveriam se sentir livres para inventar os métodos capazes de resolver os problemas das pesquisas que estão fazendo.

Respondendo às críticas feitas pelo historiador Jacques Leonard a seu livro Vigiar e punir, ${ }^{1}$ em 1980, no texto "A poeira e a nuvem", Foucault (1994) diferencia o trabalho histórico feito a partir da análise de um período, daquele feito a partir da análise de um problema. Para quem estuda um período ou uma instituição durante um dado período, é necessário atenção a duas regras: o tratamento exaustivo de todo o material e a eqüitativa repartição cronológica do exame. Contudo, quem quer tratar, através da genealogia, de um problema surgido em um dado momento, deve seguir outras regras:

[...] escolha do material em função dos dados do problema; focalização da análise sobre os elementos suscetíveis de resolvê-lo; estabelecimento das relações que permitem essa solução. E, portanto, indiferença para com a obrigação de tudo dizer, mesmo para satisfazer o júri dos especialistas convocados. [...] O trabalho assim concebido implicava um recorte segundo pontos determinantes, e uma extensão segundo relações pertinentes" (FOUCAULT, 2003a, p. 326). 
Seu método nasce da necessidade de análise do problema, e é por este modulado. A avaliação deve, portanto, se dar a partir da pertinência dos procedimentos em relação à solução do problema escolhido. A adequação dos procedimentos ao critério das orientações metodológicas consagradas torna-se secundário.

Mas, e o "júri dos especialistas" ao qual se refere na citação? O conhecimento não está imune de ser avaliado, julgado por especialistas da chamada comunidade científica. Além disso, o júri dos especialistas, em suas diferentes modalidades, participa diretamente das condições de possibilidade para a produção de pesquisas através de um sistema institucionalizado que determina não somente sua avaliação, mas também seu financiamento. Por isso, a indiferença para com eles, preconizada por Foucault, nem sempre é possível. Esse “júri” possui uma ação técnica, mas sua função é também política e mercadológica. Por isso torna-se necessário construirmos um diagnóstico de sua atuação e desenvolvermos estratégias para lidar com suas exigências e influências.

\section{Elementos Para UM diagnóstico do CAMPo dA PESQUiSa No BRASIL}

Chauí (2001) traz elementos importantes para construção de um diagnóstico inicial da pesquisa ao analisar o atual momento da universidade brasileira. Ela a descreve como sendo uma "universidade operacional" - regida por contratos de gestão, avaliada por índices de produtividade, estruturada por estratégias e programas de eficácia organizacional. Sintoma disso é a tendência de aumento das horas-aula, a diminuição dos prazos para conclusão dos mestrados e doutorados, a avaliação quantitativa das publicações, congressos e produções técnicas, multiplicação dos relatórios, reuniões, comissões, e comitês, etc. Na pós-graduação conduzida pelas universidades confessionais e privadas a situação ganha conteúdos mais sombrios, à medida que a gestão acadêmica fica, cada vez mais, abertamente atrelada à contabilidade. Em todas as instituições de ensino superior, públicas ou privadas, encontramos um permanente aumento de exigências feitas a docentes e discentes de ações exteriores ao trabalho intelectual.

Nesta universidade operacional a pesquisa tornou-se uma

[...] estratégia de intervenção e de controle de meios ou instrumentos para a consecução de um objetivo delimitado [...] Pesquisar ali, não é conhecimento de alguma coisa, mas posse de instrumentos para intervir e controlar alguma coisa [...] A avaliação desse trabalho só pode ser feita em termos compreensíveis para uma organização, isto é, em termos de custo-benefício, pautada pela idéia de produtividade, que avalia em quanto tempo, com que custo e quanto foi produzido" (CHAUÍ, 2001, p. 192).

Nessa mesma direção discorrem Arantes, Lobo e Fonseca (2004), apontando que os atuais critérios de avaliação da pós-graduação, em sua sobrevalorização de artigos publicados em revistas indexadas, trazem como conseqüência a desvalorização do educador e do debate acadêmico fora dos muros da universidade. 
Para esse "sistema de avaliação não existem mais docentes, apenas pesquisadores que têm que escrever meia dúzia de artigos eruditos em revistas indexadas, lidos somente por meia dúzia de outros pesquisadores" (ARANTES; LOBO; FONSECA, 2004, p. 65). Esse sistema, por mais amplo que seja, mesmo globalizado, aprimora os laços internos aos pesquisadores, negligenciando o debate fora do meio estritamente universitário.

Luz (2005) desenvolve um estudo sobre o regime de produção intelectual da pesquisa na universidade brasileira, a partir da categoria de "produtividade". Em sua ótica, esta categoria, "interiorizada das atividades econômicas para o trabalho intelectual" (LUZ, 2005, p. 43), tem efeitos perversos tanto sobre os produtores-pesquisadores, quanto sobre o produto-pesquisa.

Ela aponta que as atividades de pesquisa estão concentradas nos programas de pós-graduação e seus principais atores, os docentes, foram transformados essencialmente em pesquisadores. A maior parte do custo das pesquisas é realizada pelas agências de fomento estatais, através de editais que induzem:

[...] de acordo com os variáveis interesses da política governamental, não apenas os eixos temáticos de investigação (o que pesquisar), como também o roteiro metodológico a ser seguido pelos pesquisadores (como pesquisar), e a lista de "produtos" que devem resultar do processo da pesquisa (os resultados). O pesquisador é avaliado pela quantidade de produtos que é capaz de extrair de seus projetos. Quanto mais produtos, maior sua 'produtividade' (LUZ, 2005, p. 44).

Nessa universidade operacional o projeto de pesquisa passa a ter um valor superestimado. Ele é o fiador que garante a produção de resultados. Por isso ele deve detalhar seus aspectos operacionais, em detrimento de sua problematização conceitual. Por isso os projetos devem apresentar com clareza os objetivos e as metas a serem alcançados, a metodologia empregada entendida como descrição operacional dos procedimentos, as contribuições científicas e tecnológicas da proposta, o orçamento e cronograma detalhados (CNPq, 2008). O acento, portanto, está colocado na dimensão do "produto" que o projeto poderá fornecer. Para isso a metodologia é solicitada como um plural de estratégias de ação, passos a serem seguidos dentro de um cronograma "de execução", com uma ótica antecipatória, tudo minuciosamente descrito.

Vemos, portanto, a partir desses estudos, que a produção de pesquisas se constitui como um campo onde forças estatais e de mercado (esferas que pouco se distinguem hodiernamente) afirmam, mediante um conjunto de recursos legais, financeiros, regulatórios, entre outros, operacionalizando uma poderosa determinação nas formas e conteúdos dos trabalhos. Esse molde repercute, conforme indica Luz (2005), tanto sobre a produção das pesquisas, quanto a dos pesquisadores, em decorrência de uma concepção operacional do que é pesquisar. Entretanto, se entendemos, com Foucault (1984, p. 13), que o "corpo vivo" da pesquisa 
é o "ensaio - como experiência modificadora de si no jogo com a verdade, e não como apropriação simplificadora de outrem para fins de comunicação", temos um conflito instalado.

Por essa razão, pesquisar no Brasil hoje se torna também um enfrentamento do instituído não somente no âmbito da produção inventiva de conhecimento e de subjetivação, mas também no desenvolvimento de estratégias e táticas de manejo desse "júri de especialistas", entendido como um sistema de saberes e poderes institucionais que estabelecem os critérios de avaliação e financiamento das pesquisas.

Esse júri tem sua composição escolhida entre pares, geralmente de carreira mais consolidada (LUZ, 2005), e sua atuação tende ao fortalecimento do instituído, ou, na linguagem foucaltiana, à manutenção de uma hegemonia na relação de forças (FOUCAULT, 2004), através de um conjunto de técnicas de governo apresentadas através de formulários, regulamentos, portarias, estabelecimento de critérios de avaliação, padronização de procedimentos, implantação de políticas. Evidentemente, esse manejo de governamentalidade se impõe sobre um coletivo caracterizado por amplas variações, diversidade de interesses e tendências, marcadas tensões, que mantém entre si contínuos jogos estratégicos de poder. Coletivo que não se constitui como grupo de pares fechado sobre si mesmo, mas como sistema aberto permanentemente atravessado por fatores heterogêneos, tais como políticas de educação, conjuntura econômica, parâmetros internacionais de produção, tendências teóricas e ideológicas, etc. Porém, há que se lembrar que tal política de pesquisa está inserida num universo cultural decididamente cartesiano, pautado em um projeto marcado pelo protocolo das "idéias claras e distintas", em uma estratégia de ação portadora de garantias de um conhecimento operativo e verdadeiro, trazendo consigo um reconhecimento naturalizado e ampliado.

Um exemplo desse universo cultural cartesiano pode ser vislumbrado através de um pequeno levantamento realizado junto a uma turma de novos mestrandos de psicologia (entrada em 2006), em que se buscou conhecer através de duas questões abertas as concepções e as opções metodológicas que pautaram a elaboração de seu projeto de pesquisa. Havia 19 alunos presentes e 18 responderam às questões.

Uma análise de conteúdo das respostas, privilegiando principalmente critérios de repetição e relevância indica que a ampla maioria dos alunos entende a metodologia como um modo de "direção, orientação, planejamento" do caminho da pesquisa. Vários se referem a ela como procedimento de "coleta, análise e interpretação dos dados" que permite o estabelecimento da relação entre teoria e material empírico. Outros tantos demonstram preocupação direta de seu uso como assegurador da validação científica do trabalho. Mesmo quando seus projetos apresentam concepções teóricas e conceituais mais sofisticadas, sua reflexão metodológica inicial está marcada por uma concepção de metodologia entendida como prescrição operacional do como deve ser feito um trabalho de cunho "científico". Apresentam expressões que descrevem a função da metodologia como sendo a de "fundamentar o caminho a seguir", "tornar a pesquisa aceitável dentro 
dos padrões de produção científica", "base do desenvolvimento do trabalho" ou, como metaforiza outro aluno, "é como um mapa que precisamos para conhecer o lugar". Em suma, tal como preconiza Descartes, a metodologia é pensada por esses pós-graduandos iniciantes como sujeito, subjectus (aquilo que subjaz, fundamento), da pesquisa.

Não é demais lembrar que a CAPES espera, por parte dos programas de pós-graduação, um produto final - suas dissertações defendidas num prazo de dois anos. Disso decorre que o trabalho de orientação tem seu horizonte delimitado por uma ação que obtenha resultados de qualidade, circunscrito por um tempo de conclusão que inevitavelmente acarreta efeitos sobre o processo. O desafio presente da orientação, tanto numa perspectiva genealógica, quanto em perspectivas afins ${ }^{2}$ consiste em favorecer a autonomia do pesquisador em formação, face às pressões sofridas pelos programas de pós-graduação no que tange a avaliações e exigências de "produtividade". Em concordância com Deleuze (1999) lembramos que o primeiro ato de um pesquisador consiste na recusa do instituído. E o que é urgente em nossa atualidade não é a resolução dos falsos problemas ou dos problemas mal colocados, mas a colocação apropriada dos verdadeiros problemas. Esse ato, ao mesmo tempo epistemológico e político, é o que nos distancia da condição de aluno, que somente busca a solução do problema dado pelo professor e nos instala na condição de pesquisador, que exerce sua liberdade de investigação na constituição dos próprios problemas.

\section{Algumas direções de trabalho}

A partir do esboço diagnóstico de questões que atravessam o trabalho de pesquisa e orientação na pós-graduação, cumpre trazer algumas indicações de direções de trabalho nesse âmbito, tanto da prática de pesquisa, quanto da prática de orientação, lembrando que, em última instância, tratam-se de atividades investigativas, seja a do professor, seja a do pós-graduando.

No que tange à elaboração da pesquisa, um aspecto presente no percurso de Foucault merece ser destacado. Apesar de recusar a idéia da metodologia como um a priori da pesquisa, Foucault buscou sempre explicitar quais foram, em cada caso, suas escolhas metodológicas, e por que as fez. Certa discussão "metodológica" acompanha a maior parte de sua obra. ${ }^{3}$ Seja em seus próprios livros, seja nas entrevistas nas quais os comentava. Foucault sempre se mostrou disponível e disposto para a discussão metodológica. Vimos isso no debate, mencionado anteriormente, de Foucault com um dos membros do "júri de especialistas", o historiador, que questionava sua pesquisa relatada em Vigiar e punir. E, neste caso, ele não se furtou a esclarecer suas escolhas metodológicas e diferenciá-las de posicionamentos mais clássicos (FOUCAULT, 2003a). Nesse aspecto, junto com a inovação que sua pesquisa genealógica promoveu, Foucault era portador de uma virtude "clássica" na pesquisa: ser explícito na exposição de como conduziu seu processo de investigação (BAUER; GASKELL, 2002). Portanto, a discussão metodológica merece ser reconhecida como elemento vital na produção de conhecimento 
e deve ser entendida mais amplamente do que a simples descrição operativa de procedimentos que é solicitado nos projetos das agencias de fomento. Ela envolve também os importantes aspectos conceituais, éticos e políticos.

Quanto ao projeto de pesquisa, a partir do qual se decidem as possibilidades de financiamento para o pesquisador, vale lembrar sua dimensão estratégica e tática. Recentemente a geneticista da USP, Mayana Zatz (2007, p. 8), declarou em um debate promovido pela Folha de São Paulo: "Quem coloca a mão na massa sabe quais são as limitações. Às vezes, você tem de vender o peixe quando precisa de financiamento. [...] A gente tenta dourar um pouquinho a pílula". Existe indicada nessa fala uma dimensão tática, que compõe a elaboração de um projeto de pesquisa que busca financiamento. Implica, de certo modo, "vender o peixe", para repetir a expressão coloquial expressa no debate. Se essa ação tática, de $m a-$ rketing, tem uma grande importância quando se trata da busca de financiamento, não é necessário outorgar a esse aspecto função maior do que ele possui, ou seja, a de meio. Do ponto de vista da elaboração do trabalho um bom projeto porta outros aspectos mais cruciais que a necessária apresentação operativa dos procedimentos, tais como a elaboração reflexiva inicial daquilo que já se configura como início da investigação e a construção do problema a ser enfrentado.

Retomando o tema da orientação, o que encontramos freqüentemente na pós-graduação é o trabalho inicial do orientando surgir, muitas vezes, cindido entre parte teórica e parte empírica, apresentadas em justaposição. Em outros casos o vocabulário conceitual do (s) autor (es) se espalha, na forma de jargão, por todo o escrito, em detrimento de sua utilização como instrumento de pensamento. Como contraponto a isso, vale lembrar a descrição que Foucault fazia sobre sua relação essencial com a obra de Nietzsche: "os autores eu gosto, eu os utilizo" (FOUCAULT, 1979, p. 143), e não reproduzir, via exegese do texto, o que o autor disse originalmente, reificando o campo problemático onde sua obra foi produzida, e fazendo uma aplicação direta sobre um campo problemático atual. Trata-se de utilizar ferramentas conceituais do autor referido dentro do campo problemático que se investiga, mesmo que seja ao custo de certa "infidelidade" ao autor utilizado. Importa "precisamente utilizá-lo, deformá-lo, fazê-lo ranger, gritar" (FOUCAULT, 1979, p. 143). Por essa razão a obra de Foucault foi classificada como uma "análise de dispositivos concretos" (DELEUZE, 1995, p. 155), e não um estudo ou comentário de textos teóricos importantes. Além disso, uma boa pesquisa não conversa somente com os teóricos de referência, muitas vezes distantes da área específica que está sendo investigada, mas também com outros pesquisadores que já se debruçaram sobre o mesmo tema. Ou seja, associa o chamado "marco teórico" com o "estado da arte".

Uma pesquisa genealógica se estabelece através da utilização de autores e conceitos para enfrentamento de um problema. Vai além, portanto, da simples "revisão bibliográfica", acompanhada, na descrição feita por um dos mestrandos mencionados, de uma "verificação no campo", num movimento que na maior parte dos casos torna-se de confirmação ou aplicação da teoria. Exige, por parte do pesquisador, uma passagem entre a simples aplicação, para a "utilização" de conceitos a serviço de um problema, núcleo de força da investigação. Entretanto, 
essa passagem entre a exposição e a utilização de um pensamento nem sempre é realizada de modo ameno, por parte dos pós-graduandos, ainda que seja prérequisito para conduzi-los à condição de pesquisadores, mostrando-se capazes da elaboração de um trabalho autoral, meta maior da pós-graduação.

Renato Janine Ribeiro (2003) discute esse problema se perguntando o porquê dos trabalhos acadêmicos em ciências humanas e sociais serem tão tímidos e limitados na abordagem de seus temas. Sua hipótese é de que muitos alunos seguem um caminho conservador de procurar uma bibliografia de referência e "aplicá-la" a um objeto, tornando o tema da pesquisa uma mera ilustração de um estudo bibliográfico. Segundo ele, os pesquisadores se abrigam no manto de autoridade de autores já consagrados para evitar a ansiedade de se exporem ao tema escolhido, em geral difícil e tentador, produzindo assim "um esvaziamento do desejo de pensar" (RIBEIRO, 2003, p. 125). Isso porque em ciências humanas os temas de pesquisa estão intimamente vinculados com o desejo do pesquisador, o que produz, ao mesmo tempo, atração e temor. "As Humanas se caracterizam por uma profunda perturbação nas relações entre sujeito e objeto [...] freqüentemente, aquilo que ele [o pesquisador] diz sobre o objeto contém também um discurso sobre o sujeito da pesquisa" (RIBEIRO, 2003, p. 88). Sua sugestão é que os pesquisadores deveriam se expor mais a seus objetos, assumindo a função de subjetivação imanente à pesquisa.

Dito de outro modo, a pesquisa pode ser entendida como a produção de "uma experiência em que o sujeito e o objeto se formam e se transformam um em relação ao outro e em função do outro [...], pois o sujeito é constituído na imanência de um campo de conhecimento" (FOUCAULT, 2004, p. 237). No trabalho genealógico produção de conhecimento, relações de poder e produção de subjetividade apresentam-se como indissociáveis. E essa indissociabilidade não deve fazer parte dos jogos de bastidores da pesquisa que devam, necessariamente, ser ocultados.

Outra discussão essencial sobre pesquisa consiste em analisar seu propósito, clarificando sua função: afinal, para que serve a pesquisa? Podemos começar com uma resposta inicial formal: uma pesquisa serve para resolver um problema (RICHARDSON et al., 1999) e esse problema deve possuir relevância, social, teórica e/ou metodológica. Ribeiro (2003, p. 101) especifica essa relevância social apontando que as pesquisas em ciências humanas e sociais nascem de um mal-estar na cultura e por isso "buscam conhecer seu objeto a fim de mudá-1o". Ou seja, na melhor tradição da psicologia social de Kurt Lewin (1983, p. 217) a pesquisa "leva à ação social. Pesquisa que produza apenas livros não será o bastante". Ribeiro (2003) também considera que essa mudança pode ser pensada em decorrência de dois dos destinatários principais desses trabalhos. O primeiro é o mercado que as financia: "o Estado e o para-Estado das ONGs" (RIBEIRO, 2003, p.103). Isso pode produzir intervenções em realidades localizadas e mesmo a utilização dos resultados na elaboração de políticas públicas. Mas há também um segundo destinatário, mais difuso, que é "a formação de uma opinião pública à luz das grandes descobertas em ciências humanas" (RIBEIRO, 2003, p. 103), que produziria num prazo mais longo uma opinião pública democrática. 
Vemos esses efeitos bastante presentes nas discussões feitas em torno de temas como democracia, políticas de conselhos, segurança pública, políticas de saúde e de educação, infância e juventude, drogas, raça, gênero, entre outros (GARCIA; LANDIM; DAHMER, 2003).

A pesquisa genealógica consiste em tomar a investigação não como representação adequada ou verdadeira de uma realidade investigada (como faz Descartes), mas como um instrumento instaurador de realidades, portador de uma materialidade própria que objetiva a intervenção em outras materialidades. Assim Foucault (2006, p. 76) descrevia sua pesquisa de doutorado publicada como a História da Loucura: ${ }^{4}$

\begin{abstract}
Meu trabalho estava diretamente ligado à forma das portas dos asilos, à existência das fechaduras, etc. Meu discurso estava ligado a esta materialidade, a estes espaços fechados, e eu queria que as palavras que eu tinha escrito atravessassem muros, fizessem saltar fechaduras, abrissem janelas!
\end{abstract}

Ou seja, para Foucault, os livros (e outros produtos de pesquisas) não devem ser apenas livros, mas instrumentos discursivos portadores de uma materialidade própria, capazes de produzirem efeitos que ultrapassam a intencionalidade do autor. Podem assim, contribuírem para a formação de uma opinião pública democrática, podem se conectar com movimentos políticos e sociais potencializando sua ação (como ocorreu com seu História da loucura), podem enfim "dar o máximo de oportunidades à multiplicidade, ao encontro, ao impossível, ao imprevisível" (FOUCAULT, 2006, p. 99). Enfim, pesquisamos não apenas para caracterizar certo estado das coisas, mas buscando as linhas de vulnerabilidade de nossa atualidade, de modo a promover espaços de "transformação possível" (FOUCAULT, 2000, p. 325).

\title{
Notas
}

${ }^{1}$ (FOUCAULT, 1987).

${ }^{2}$ Foucault $(1979$, p. 168) jamais reivindicou para sua genealogia uma condição de absoluta originalidade no campo da pesquisa e da intervenção, ele a colocava num campo mais amplo das "ofensivas dispersas e descontínuas", ao lado de outras abordagens.

${ }^{3}$ Além das referências já mencionadas vale conferir suas quatro "precauções metodológicas" (FOUCAULT, 1979, p. 182-184) e seus três princípios metodológicos (FOUCAULT, 2004, p. 237-238), entre outras.

${ }^{4}$ (FOUCAULT, 2003b). 


\section{REFERÊNCIAS}

ARANTES, E. M. M.; LOBO, L. F.; FONSECA. T. M. G. Pensar: a que será que se destina? Diferentes tempos de uma reflexão sobre a morte anunciada do educador. Psicologia \& Sociedade, Florianópolis, v. 16, n. 1, p. 50-68, 2004. Número especial.

BAUER, M. W.; GASKELL, G. Pesquisa qualitativa com texto, imagem e som: um manual prático. Petrópolis: Vozes, 2002.

BECKER, H. Métodos de pesquisa em ciências sociais. 4. ed. São Paulo: Hucitec, 1999.

CHAUÍ, M. Escritos sobre a universidade. São Paulo: UNESP, 2001.

CNPq. Edital CNPq MCT/CNPq N 014/2008 - Universal. 2008.

DELEUZE, G. ¿Qué es um dispositivo? In: BALBIER, E. et. al. (Ed.). Michel Foucault: filósofo. 2. ed. Barcelona: Gedisa, 1995. p. 155-163.

. Bergsonismo. São Paulo: Ed. 34, 1999.

DESCARTES. Discurso do Método. 3. ed. São Paulo: Abril Cultural, 1983. Coleção "Os Pensadores"

FERREIRA NETO, J. L. A formação do psicólogo: clínica, social e mercado. São Paulo: Escuta 2004.

FOUCAULT, M. A Arqueologia do Saber. Petrópolis: Vozes, 1972. . Microfisica do poder. Rio de Janeiro: Graal, 1979.

- Vigiar e Punir: nascimento da prisão. Tradução de Lígia M. Ponde

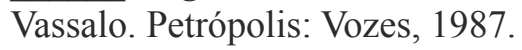

1984. v. 2.

. História da sexualidade: o uso dos prazeres. Rio de Janeiro: Graal, . Dits et écrits. Paris: Gallimard, 1994. v. 4.

. Arqueologia das ciências e história dos sistemas de pensamento. Rio de Janeiro: Forense-Universitária, 2000.

. Estratégia poder-saber. Rio de Janeiro: Forense Universitária, 2003a.

. História da loucura. Tradução de José Teixeira Coelho. São Paulo: Perspectiva, 2003b. 
FOUCAULT, M. Ética, sexualidade, politica. Rio de Janeiro: Forense Universitária, 2004.

. Eu sou um pirotécnico. In: POL-DROIT, R. (Ed.). Michel Foucault: entrevistas. Rio de Janeiro: Graal, 2006.

GARCIA, J.; LANDIM, L.; DAHMER, T. (ORG.) Sociedade e políticas: novos debates entre ONGs e universidade. Rio de Janeiro: Revan, 2003.

LEWIN, K. Problemas de dinâmica de grupo. São Paulo: Cultrix, 1983.

LUZ, M. T. Prometeu acorrentado: análise sociológica da categoria produtividade e as condições atuais da vida acadêmica. PHYSIS: Rev. Saúde Coletiva, Rio de Janeiro, v. 15, n. 1, p. 39-57, 2005.

RIBEIRO, R. J. A universidade e a vida atual: Fellini não via filmes. Rio de Janeiro: Campus, 2003.

RICHARDSON, R. J. et. al. Pesquisa social: métodos e técnicas. 3. ed. São Paulo: Atlas, 1999.

ZATZ, M. A hélice dupla e as duas culturas. Folha de São Paulo. São Paulo, 01 abr. 2007. Caderno Mais, p. 8.

Recebido em: setembro de 2007

Aceito em: dezembro de 2008 